\title{
The Behaviour of a Reinforced Soil Mattress Spanning a Cavity Modelled in a \\ Geotechnical Centrifuge
}

C. Van Dyk and S.W. Jacobsz*

Department of Civil Engineering, University of Pretoria, Pretoria, South Africa

\begin{abstract}
Sinkholes can occur on land underlain by dolomite and cause substantial damage to buildings and even loss of life. More than four million people work or reside on dolomite land in South Africa and it is therefore important to be able to construct safely on dolomite land and to minimise the risk of damage to infrastructure and loss of life. Compacted soil mattresses are often used to found structures on areas underlain by dolomite. This study investigated the effect of tensile reinforcement on the behaviour of a soil mattress spanning an underlying water filled cavity designed to impose a cover subsidence sinkhole. Three small-scale models, each consisting of a soil mattress with a cover subsidence sinkhole forming underneath, were constructed and tested in a geotechnical centrifuge. In the first test, an unreinforced soil mattress was tested and in two more tests, reinforced soil mattresses with different reinforcement strengths were tested. The settlement of the unreinforced soil mattress was initially less than that of the reinforced soil mattresses up to the point at which it failed suddenly. Neither of the reinforced soil mattresses failed suddenly, but both experienced large surface settlements that would have led to substantial damage to an overhead structure.
\end{abstract}

Keywords: cavity, centrifuge, geosynthetic reinforcement, sinkhole, soil mattress

*Corresponding author: Prof SW Jacobsz, Dept Civil Engineering, University of Pretoria, Pretoria, 0002, South Africa. Tel +27 12420 3124; Fax: +27 12362 5218; Email: sw.jacobsz@up.ac.za

\section{INTRODUCTION}

Sinkholes can form at the ground surface in areas underlain by dolomite rock. A cover collapse sinkhole is a sudden manifestation of a hole at the ground surface due to the collapse of the roof of a cavity in the ground, while a cover subsidence sinkhole is a depression at the ground surface which forms gradually (Beck \& Sayed 1991; Culshaw \& Waltham 1987). Damage caused to buildings and other structures on dolomite has been far more severe than on any other geological formation in southern Africa (Brink 1979), with the damage to 
properties over the 40 years preceding 2000 exceeding US\$100 million (Buttrick et al. 2001). To date, 38 people have lost their lives in sinkholes on dolomite land in South Africa, with no loss of life in a sinkhole reported since the early 1970s (Buttrick et al. 2001). The authors are also not aware of any loss of life in recent years.

According to Van Schalkwyk (1981), twenty percent of the densely populated Gauteng Province (the PretoriaJohannesburg-Vereeniging area, see Figure 1) is underlain by dolomite. Most of the gold mining areas in the North-West Province and the Far West Rand are also underlain by dolomite. Currently four to five million people work or reside on dolomite land (Buttrick et al. 2011). It is therefore important to be able to develop in these areas and to minimise the risk of damage to infrastructure and loss of life.

\section{DOLOMITE}

\subsection{Dolomite land}

Some exposures of dolomite bedrock in South Africa are illustrated in Figure 1. The South African National Standard for development of dolomite land (SANS 1936, 2012) defines "dolomite land" as land underlain by dolomite or limestone residuum or bedrock (or both) at depths of up to $60 \mathrm{~m}$. In areas where dewatering of the underlying aquifers has occurred or is occurring, the Standard recommends that this depth be increased to $100 \mathrm{~m}$ due to the increased risk of sinkhole formation under such conditions. Dolomite land, typically associated with the Transvaal and Griqualand West basins of the Transvaal Supergroup, is found in several provinces in South Africa namely Gauteng, Limpopo, the Northern Cape and North-West Province. The most important dolomitic rocks are found in the Chuniespoort Group, specifically the Malmani Subgroup, as these underlie economically important mining areas and urban centres like Centurion south of Pretoria. Also of significance are the dolomites of the Ghaap and Griqualand West sub-basins in the Northern Cape where dolomite occurrence impacts on some mining activities (Johnson et al. 2006; Wagener 1984; SANS 1936 2012). 


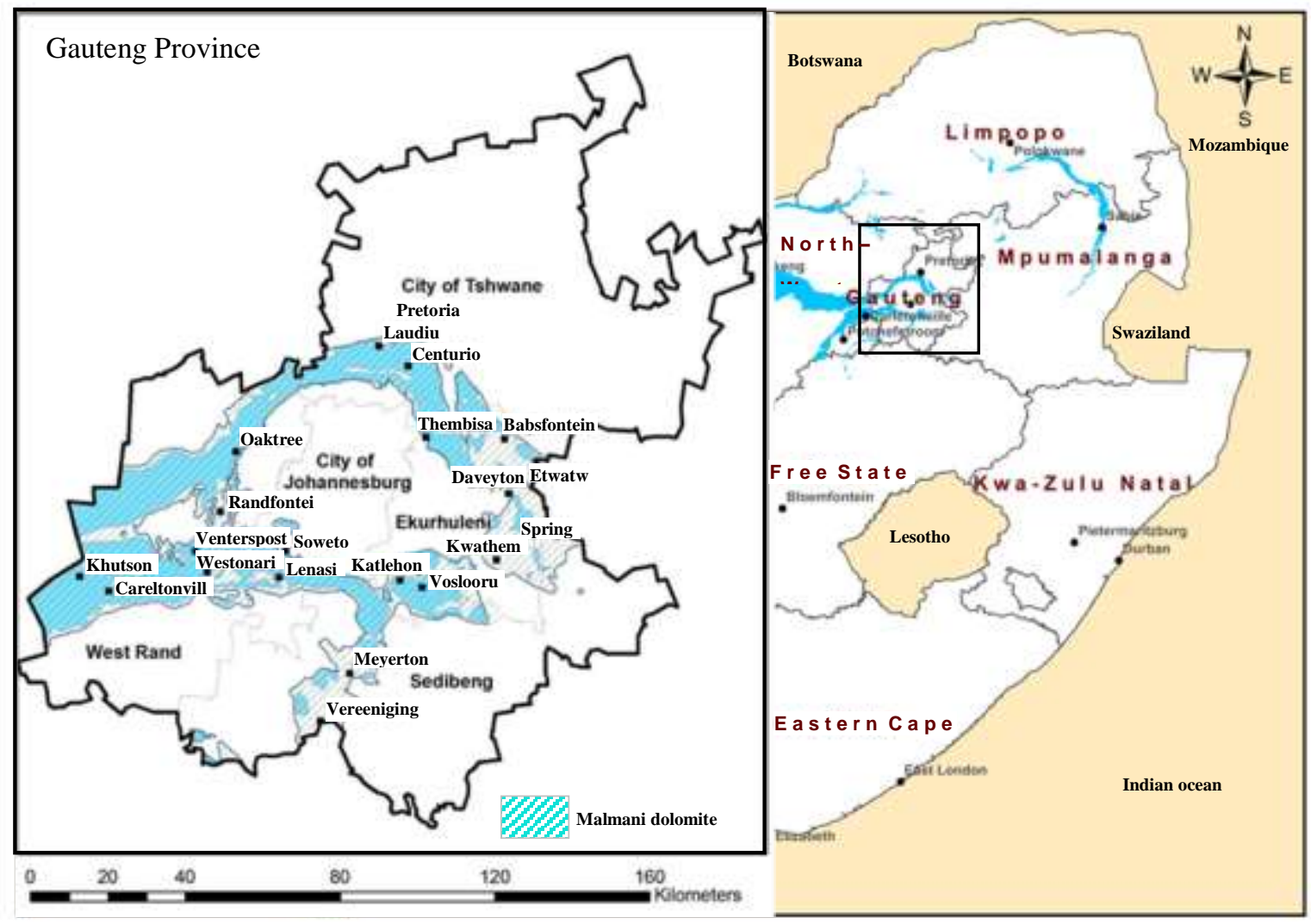

Fig. 1 The distribution of dolomite rock in the east of South Africa and Gauteng Province. (Source: South Africa Council of Geosciences).

\subsection{Weathering of dolomite rock}

Dolomite is a carbonate mineral $\left(\mathrm{CaMg}\left(\mathrm{CO}_{3}\right)_{2}\right)$ with a crystal lattice consisting of alternating calcium $(\mathrm{Ca})$ and magnesium $(\mathrm{Mg})$ ions, separated by carbonate $\left(\mathrm{CO}_{3}\right)$ layers. In the Transvaal Supergroup, the dolomite rock comprise of a series of alternating bands of dolomite and insoluble chert. Dolomite rock is insoluble in pure water and has a low porosity. However, weak carbonic acid, rain water which has become charged with carbon dioxide when passing through the atmosphere and soil, can dissolve dolomite rock over time. Discontinuities in the dolomite rock can act as passages for this rainwater to flow through and slowly dissolve the rock (Brink 1979). This solution of the dolomite rock can lead to the formation of rock pinnacles as material along vertical joints gradually corrodes away. The solution of the rock can also lead to fractures being widened to form slots and grykes. These slots and grykes can extend below the water table and further solution can lead to the formation of cavities and caverns within the bedrock, contributing to a karstic rock head topography. 


\subsection{Formation of sinkholes}

Dissolution of bedrock or cavities in the overburden form receptacles for material transported by subsurface erosion. Such subsurface erosion can result from concentrated water ingress, from leaking services, poorly managed surface water, or from a lowering of the water table as the water table is the baseline for subsurface erosion. This subsurface erosion may destabilise an arch in the residual material. Headward erosion results in successive arch collapses until the surface is breached and a cover collapse sinkhole manifests at the surface (Jennings et al. 1965). In instances where the overburden is too weak to span, a cover subsidence sinkhole will form. In most cases sinkholes are approximately circular in plan (Brink 1979).

\section{FOUNDING ON DOLOMITE}

Founding on dolomite is associated with a number of problems which may include (Brink 1979; Jacobsz 2013):

- the unexpected appearance of a sinkhole,

- gradual subsidence of the ground,

- compressibility of the residual dolomite material,

- the extremely non-uniform karstic rock head profile, and

- the extremely heterogeneity of the dolomite residuum and overlying transported materials complicates foundation construction.

The type of foundation chosen on dolomite land will depend on the depth of the rock (pinnacles and boulders) underlying the site in combination with the factors listed above. Various methods for founding on dolomite include conventional foundations, the use of a mattress of improved material (soil mattress), founding on the dolomite pinnacles themselves, piling, shafts, caissons, dynamic consolidation and reinforced earth solutions (Wagener 1984). This study addresses unreinforced and reinforced earth mattresses.

\subsection{Soil mattresses}

Construction of a soil mattress involves the removal of the soil-cover to a certain depth and replacing it under controlled conditions with a material of known thickness, composition and compaction. It is important for the mattress to be free draining to prevent ponding and subsequent water infiltration adjacent to the structure founded on the mattress because infiltration of surface runoff is a well-known contributing factor to sinkhole occurrences. According to Wagener (1984) the functions of a soil mattress are:

- to control total and differential settlement, 
- $\quad$ to reduce the bearing pressure on the underlying layers by spreading the load, and

- $\quad$ to reduce the risk of small sinkholes and subsidence.

Wagener and Day (1986) reported that this method of founding has been used successfully by themselves since 1975 for various industrial and domestic structures. The method has been widely used in South Africa since. A soil mattress is an economical founding solution and is often much cheaper than alternative founding solutions, for example piling. Soil mattresses do have their limitations, especially on deep sites (Wagener 1984) because the mattress required to reduce the settlement to acceptable standards becomes very thick and large in plan.

\subsection{Reinforced ground}

As mentioned above, soil mattresses have their limitations. Soil mattresses do not possess tensile strength and cannot act in tension. Metal or synthetic strips can, in principle, be provided at the bottom of the mattress to create a composite section that can act in bending, potentially spanning underlying cavities. The strips will serve as tension reinforcement and the soil will resist the compression forces. Reinforced earth mattresses can be used when it is necessary for the mattress to span a potential cavity or when the required thickness for an unreinforced soil mattress is not possible or practical (Wagener 1984). The South African National Building Regulations contained in SANS 10400 (2012) recommend that soil mattresses may require some tension reinforcement to span over potential sinkholes or between unyielding points of support. Geosynthetic materials have recently been used for soil reinforcement. Rowe \& Jones (2000) stated that the use of geosynthetic reinforcement for the support of structures over man-made or naturally occurring voids is a developing application.

\section{GEOSYNTHETICS}

Rowe \& Jones (2000) reported considerable growth during the preceding 30 years in the use of geosynthetics in civil engineering applications. Geosynthetics are made almost entirely from polymers. Examples include geotextiles, geogrids, geonets, geomembranes, geosynthetic clay liners, geopipes, geofoam and geocomposites. Both geotextiles and geogrids are suitable as basal reinforcement over karst areas (Koerner 2005). Geogrids were considered in this study.

Geosynthetics have found application as an engineering material in transport-, geotechnical-, environmental- and hydraulic engineering, as well as in private development. The application of geosynthetics in engineering solutions usually has one of two aims, namely improving the performance, or being a more economical 
alternative. They perform various functions including separation, reinforcement, filtration, drainage and containment.

\subsection{Geogrids}

The use of geogrids is increasing rapidly. They are used primarily for reinforcement. Unlike geotextiles, geogrids have an open grid structure with large apertures with individual ribs between them in both the machine and cross-machine directions. Geogrids are found in two forms, either punched thermoplastic polymer sheets or cross-laid (woven or knitted) strips (Domone \& Illston 2010; Koerner 2005).

\section{GEOSYNTHETICS USED AS REINFORCEMENT TO SPAN CAVITIES}

One method to improve the performance of foundation-fill systems, or soil mattresses overlying a material potentially containing cavities, is to provide geosynthetic reinforcement between the in-situ ground and the fill. The system can be designed either to prevent a catastrophic failure or it can be designed to reduce the settlement to acceptable values to prevent structural damage and retain serviceability (Sherif \& Jones 1996). Various guidelines are available for the design of reinforced earth systems spanning cavities. These include:

- $\quad$ British Standard (BS 8006 1995),

- South African National Standard (SANS 207 2006) (standard is based on BS 8006),

- $\quad$ the tension membrane and arching method developed by Giroud et al. (1990) and

- $\quad$ the R.A.F.A.E.L method which resulted from a French research program (Giraud 1997).

Wang et al. (1996) reported that the use of reinforced soils for bridging cavities has been limited compared to other applications due to a lack of research in this area. However, many research institutions are presently carrying out investigations into the use of geosynthetics to facilitate construction in difficult ground conditions, include the prevention of ground falls and subsidence as reported by Ponomaryov and Zolotozubov (2013). Research has shown that the performance of a soil layer spanning a cavity reinforced with a geosynthetics is affected by the strength of geosynthetic and its tensile stiffness, the strength of the compacted soil (its friction angle and cohesion), the thickness of the compacted layer and its degree of compaction (void ratio), in combination with the underlying cavity size (Sherif \& Jones 1996; Poorooshasb 1991; Wang et al. 1996). 
A physical model study was conducted in the geotechnical centrifuge of the University of Pretoria (Jacobsz et al. 2014) to investigate the influence of tensile reinforcement on the behaviour of a soil mattress spanning a cover subsidence sinkhole.

For this study four models were tested, each with a different amount of tensile reinforcement, while keeping all other parameters constant (i.e. the thickness, density and soil mattress material type, as well as the dimensions of the cavity). The first test was done with an unreinforced soil mattress, followed by two tests with different amounts of reinforcement. A fourth test was conducted with a tactile pressure sensing mat (Tekscan 2014) placed at the depth of the base of the soil mattress to assess changes in the vertical stress at the base of the mattress in response to the formation of the cavity below.

In the test with the full-strength reinforcement (Test 2), a strain gauged brass strip was placed underneath the soil mattress to provide an indication of when the reinforcement started to experience tensile strain due to the cavity forming beneath the mattress. This was done because it was not possible to fix a strain gauge on the reinforcement itself. The brass strip was roughened by gluing fine sand to it to enable it to extend with the soil around it.

\subsection{Scale laws and components requiring scaling}

To obtain similarity between the small-scale model and the full scale prototype, certain scale laws need to be applied (Lord 1987). The basic scale law of centrifuge modelling entails scaling down dimensions by a scale factor $\mathrm{N}$. To ensure vertical stress similitude at a certain depth $\mathrm{h}_{\mathrm{m}}$, the model has to be accelerated to $\mathrm{N}$ times earth's gravity. The vertical stress at a depth $h_{m}$ in the model will then be equal to the vertical stress in the prototype at depth $h_{p}$ with $h_{p}=N * h_{m}$. For various practical considerations a scale of 1:50 was adopted for this study. Various scale laws can be derived by either solving the applicable differential equations or by dimensional analysis (Lord 1987). For the experimental work of this study, three parameters had to be scaled, i.e. the linear dimensions, the particle sizes of the soil mattress material and the strength and tensile stiffness of the geosynthetic reinforcement. The scaling of particle sizes for centrifuge modelling without significantly changing material properties is complex and is a subject of ongoing research. For this project the full scale prototype particle size distribution of a typical granular fill, suitable for use in a soil mattress (discussed below), was simply divided by a factor of $\mathrm{N}=50$ to obtain the required particle size distribution for the small-scale model. 
According to Viswanadham and König (2004) there are two basic requirements for the scaling of a geogrid namely the frictional bond behaviour and tensile-strength behaviour. The frictional bond behaviour is related to the percentage open area of the geogrid and the tensile-strength behaviour is dependent on the maximum tension and the strain at which this strength is reached. The scale laws applicable to the experiment where taken from the work of Scott and Morgan (1977) and Viswanadham and König (2004) and are summarised in Table 1.

Table 1: Scale laws relevant for the experiment.

\begin{tabular}{|c|c|}
\hline Parameter & Model at $\mathrm{Ng}$ \\
\hline Linear dimensions & $1 / \mathrm{N}$ \\
\hline Stress (force/area) & 1 \\
\hline Strain (displacement/unit length) & 1 \\
\hline Density & 1 \\
\hline Geosynthetic strain (\%) & 1 \\
\hline Tensile strength of geosynthetic $(\mathrm{kN} / \mathrm{m})$ & $1 / \mathrm{N}$ \\
\hline Secant Modulus geosynthetic $(\mathrm{kN} / \mathrm{m})$ & $1 / \mathrm{N}$ \\
\hline Soil- geosynthetic friction angle (deg) & 1 \\
\hline
\end{tabular}

\subsection{The strong box and in-situ material}

The model was constructed in a strongbox with inside dimensions of 600x400x400mm high with 50mm thick aluminium alloy side walls. A fine dry silica sand was selected as the in-situ material which was to provide a medium for the sinkhole to be created in and to allow it to propagate to the surface. The properties of the sand are described by Archer (2014). The sand representing the in-situ material was placed loose $\left(\sim 1485 \mathrm{~kg} / \mathrm{m}^{3}, \mathrm{D}_{\mathrm{r}}=\right.$ 34\%). A cross-section view of the centrifuge model is presented in Figure 2. The various components are discussed below. 
LVDTs

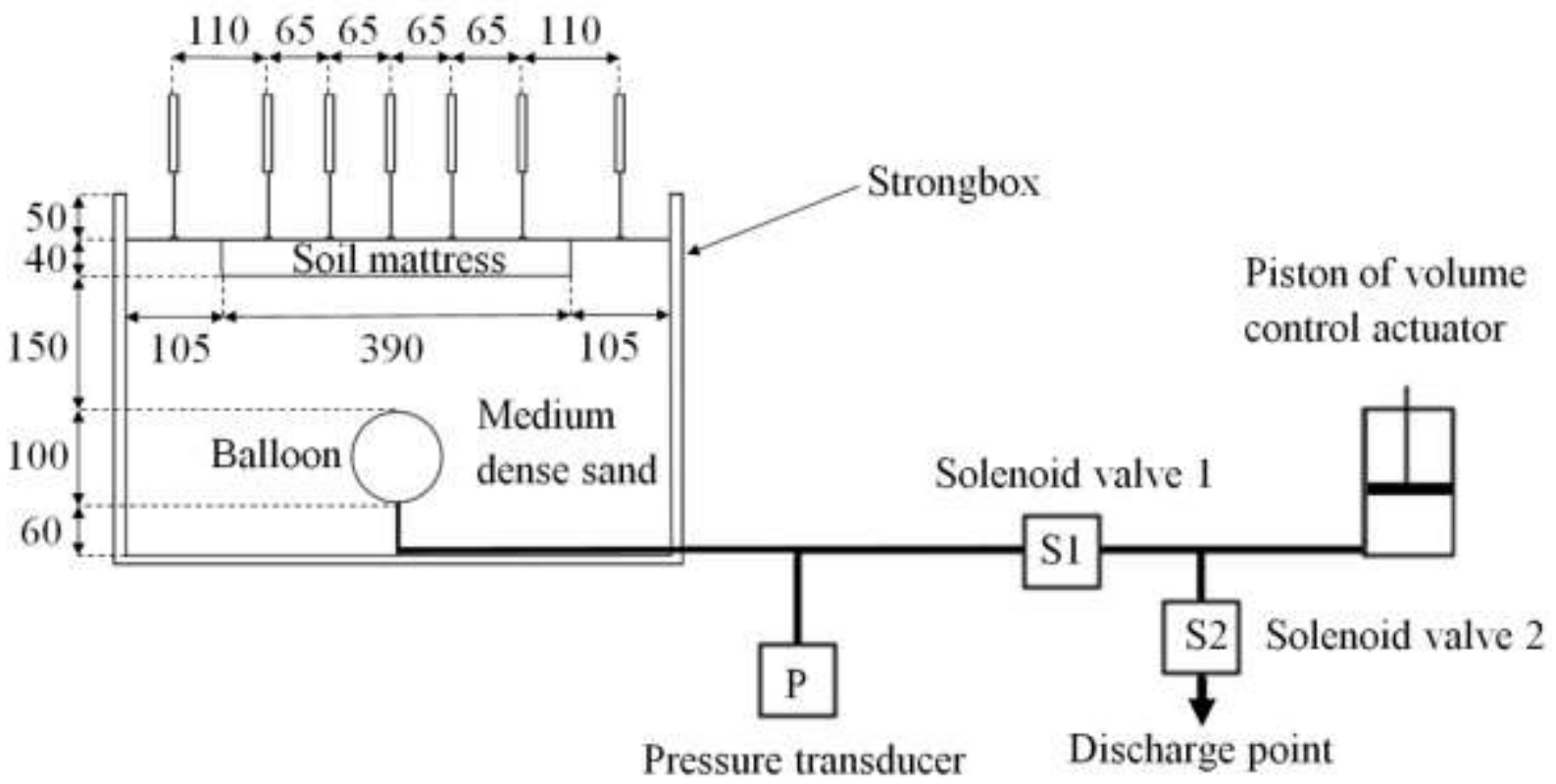

Fig. 2 Cross section view of the centrifuge model

\subsection{The model sinkhole cavity}

The formation of a cavity to create a cover subsidence sinkhole in the in-situ material was achieved by extracting water from a near-spherical water-filled balloon buried at the bottom of the in-situ material. The balloon diameter was $100 \mathrm{~mm}$ to represent a $5 \mathrm{~m}$ cavity at full scale. A $5 \mathrm{~m}$ sinkhole diameter represents the boundary between a medium and a large sinkhole according to SANS 1936 (2012). This is also the sinkhole diameter that residential dwellings need to be designed for for the worst categories of dolomitic hazard on which residential development is permitted under South African standards. The crown of the cavity was located $150 \mathrm{~mm}$ (equivalent to $7.5 \mathrm{~m}$ at the full-scale) underneath the centre of the soil mattresses.

Water was removed from the cavity using an actuator which allowed precise control over the volume of water extracted. The volume of the spherical cavity was approximately $520 \mathrm{ml}$ and the volume that the actuator could extract per stroke was $157 \mathrm{ml}$. It was therefore necessary to extract and expel the water from the balloon using a series of piston strokes.

\subsection{The soil mattress}

Recommendations in SANS 10400 (2012) suggest a $1.5 \mathrm{~m}-2.5 \mathrm{~m}$ thick mattress on sites where the depth to the dolomite pinnacles or boulders exceeds $3 \mathrm{~m}$. A $2 \mathrm{~m}$ thick prototype soil mattress was selected for this experiment which scaled to $40 \mathrm{~mm}$ in the model. A $12 \mathrm{~m}$ x $19.5 \mathrm{~m}$ prototype soil mattress was chosen, sufficient 
for a medium sized dwelling. This corresponds to model plan dimensions of $240 \mathrm{~mm}$ x $390 \mathrm{~mm}$. Soil mattress material should comply with the requirements listed in Table 2 (from SANS 207 2006).

Table 2: Grading requirements (SANS 207, 2006).

\begin{tabular}{|c|c|}
\hline $\begin{array}{c}\text { Aperture size of sieve in accodance with THM 1 } \\
\text { mm }\end{array}$ & Percentage by mass passing the sieve \\
\hline 125 & 100 \\
90 & 80 to 100 \\
75 & 65 to 100 \\
37.5 & 45 to 100 \\
9.5 & 15 to 60 \\
4.75 & 10 to 45 \\
\hline$\mu \mathrm{m}$ & 0 to 25 \\
\hline 600 & 0 to 15 \\
75 & \\
\hline Using selected granular fill either consisting of: natural gravel, natural sand, crushed gravel, crushed rock other than \\
argillaceous rock or crushed concrete.
\end{tabular}

To achieve the required scaled-down particle size distribution for the model material, a combination of different materials available were used. The final mix composition decided upon for the model soil mattress was $84 \%$ silica sand, 9\% granite sand and 7\% Kaolin (by dry mass). The Kaolin powder was added to provide some plasticity. Figure 3 presents the particle grading curve of the final mattress material used.

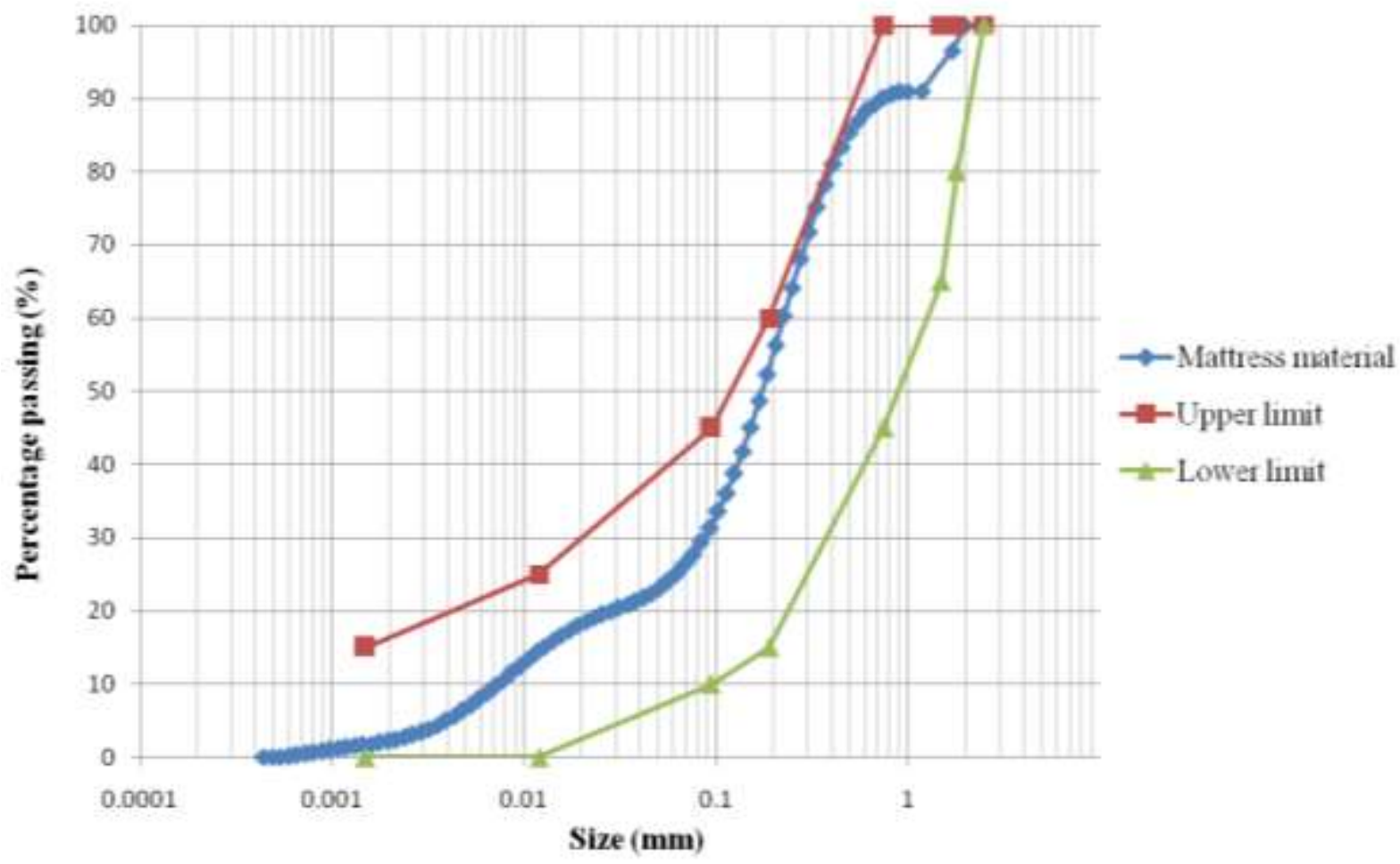

Fig. 3 Particle grading curves for the scaled mattress material 
According to SANS 10400 (2012), the soil mattress should be compacted to $95 \%$ MOD AASHTO density at $1 \%$ to $+2 \%$ of the optimum moisture content. The optimum moisture content and maximum dry density of the mattress material were determined by carrying out a scaled down version of the MOD AASHTO compaction test (TMH1 Method A7, Department of Transport 1986). The optimum moisture content calculated was $10 \%$ and the maximum dry density was $1847 \mathrm{~kg} / \mathrm{m}^{3}$.

A mould with the dimensions of the soil mattress was made in which to compact the mattress. The material was compacted in $10 \mathrm{~mm}$ layers. For the two reinforced mattresses an approximately $5 \mathrm{~mm}$ thick layer of the mattress material was placed at the bottom of the mould, followed by the reinforcement, after which the rest of the mattress was constructed as before.

\subsection{The geosynthetic reinforcement}

A glass-fibre grid was selected to use for reinforcement in the soil mattress. The grid fibres had "flat" fibre strips in one direction, with "twisted" fibre pares in the perpendicular direction. The fibre strips in both directions were spaced at $\sim 4.5 \mathrm{~mm}$. Tensile tests were done on the grid in both directions to obtain its tensile strength characteristics. As two different strengths of reinforcement were required, it was decided to cut every second strip in both directions to obtain a weaker reinforcement. The two strengths of reinforcement used are referred to as the "full-strength grid" and the "half-strength grid" respectively. At full-scale the full-strength grid represented an average maximum scale tensile strength of $755 \mathrm{kN} / \mathrm{m}$ in the "flat" direction and $1075 \mathrm{kN} / \mathrm{m}$ in the "twisted" direction. Both grids had a percentage open area of $74 \%$. Both the full-strength and half-strength grids were orientated with the "twisted" (stronger) strands in the longitudinal direction of the soil mattress.

\subsection{Measuring instruments}

Eight linear variable differential transformers (LVDTs) were used to measure the displacement on the surface of the soil in the model across the longitudinal direction in all tests. In addition, a pressure transducer was used to measure the pressure in the balloon during each experiment.

\subsection{Tests conducted}

During each test, the centrifuge was accelerated to 50G after which water was extracted from the balloon at a rate of $0.59 \mathrm{~cm}^{3} / \mathrm{s}$ to model a cover subsidence sinkhole developing below the mattress. The settlement of the soil mattress and surrounding surface was recorded using LVDTs at locations illustrated in Figure 4. 


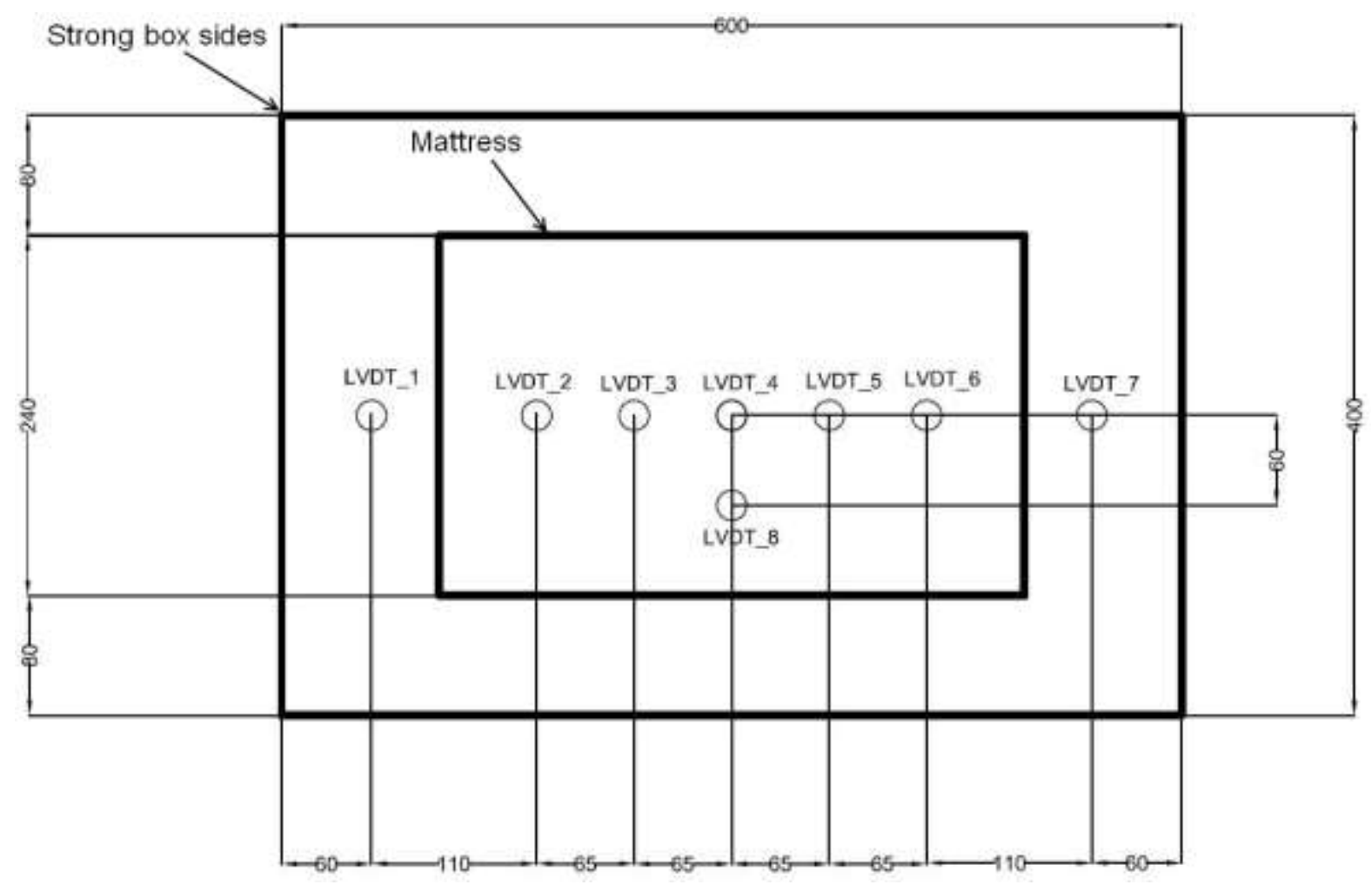

Fig. 4 LVDT layout in plan

The following tests were conducted:

- $\quad$ Test 1: A $40 \mathrm{~mm}$ thick unreinforced soil mattress.

- Test 2: A 40mm thick reinforced soil mattress with "full-strength" reinforcement.

- Test 3: A 40mm thick reinforced soil mattress with "half-strength" reinforcement.

- Test 4: This test was conducted to investigate the formation of the sinkhole on the vertical stress in the soil at the depth of the base of the soil mattress, but in the absence of a mattress. The pressure was measured with a pressure mat buried $40 \mathrm{~mm}$ below the surface and $150 \mathrm{~mm}$ above the balloon. The pressure mat is a thin flexible tactile sensor that measures interface pressures between two surfaces.

\section{PRESENTATION AND DISCUSSION OF RESULTS}

\subsection{Surface settlement profiles - Comparisons for Test 1 to 3}

The displacement profiles measured along the length of the mattress at 5\%, 20\%, $40 \%$ and $60 \%$ volume extraction are plotted in Figure 5 for mattresses with no reinforcement, full-strength reinforcement and halfstrength reinforcement respectively (Tests 1 to 3 ). 

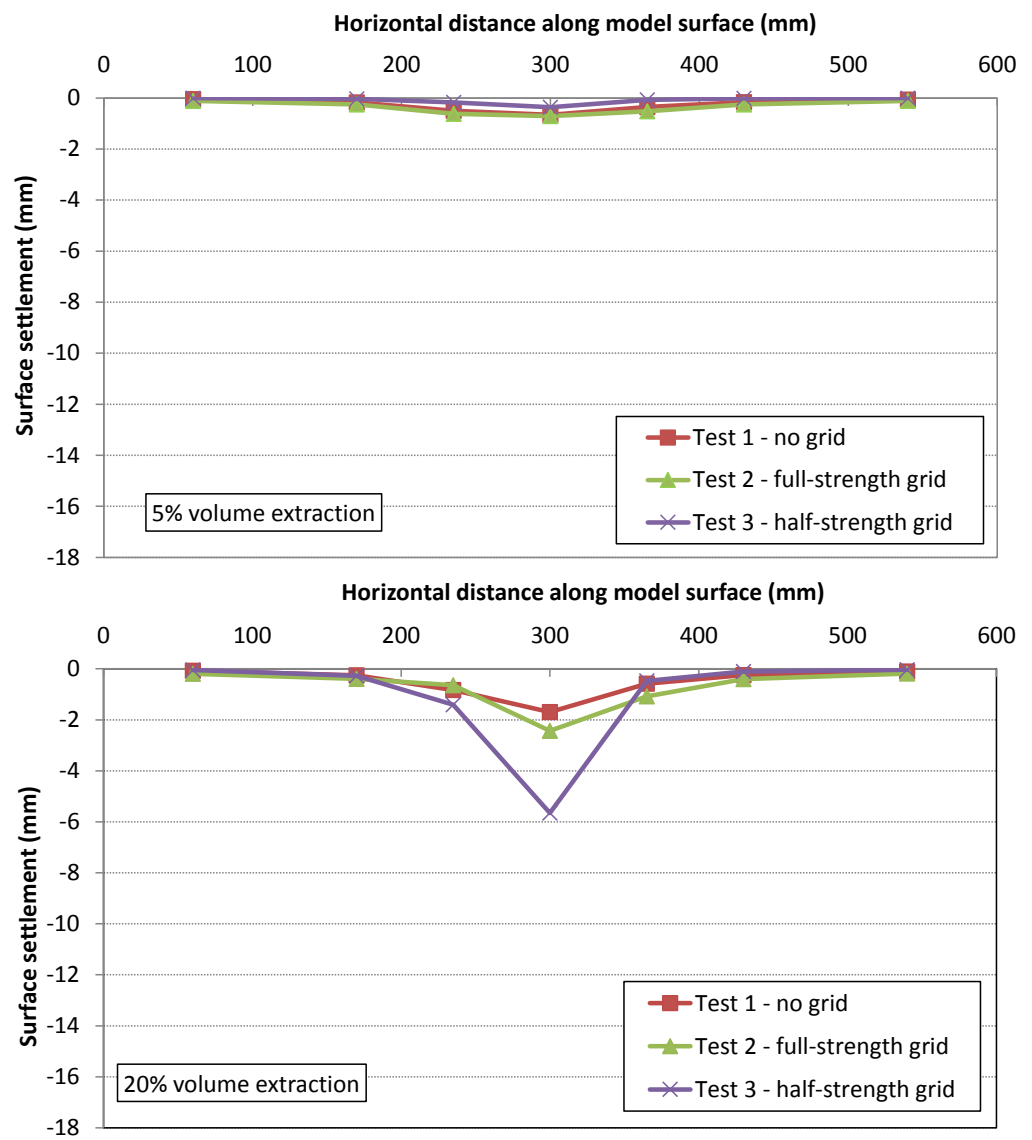

Horizontal distance along model surface $(\mathrm{mm})$

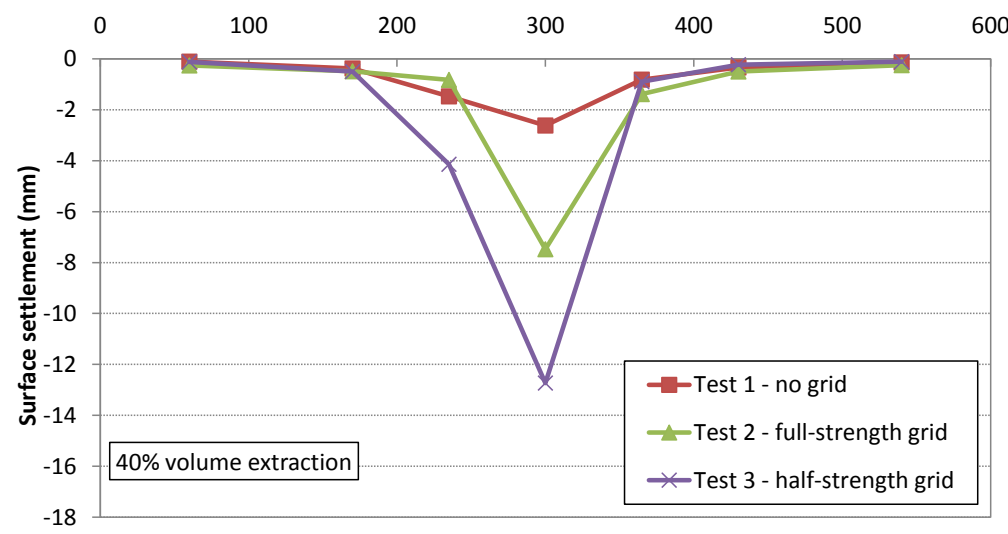

Horizontal distance along model surface $(\mathrm{mm})$

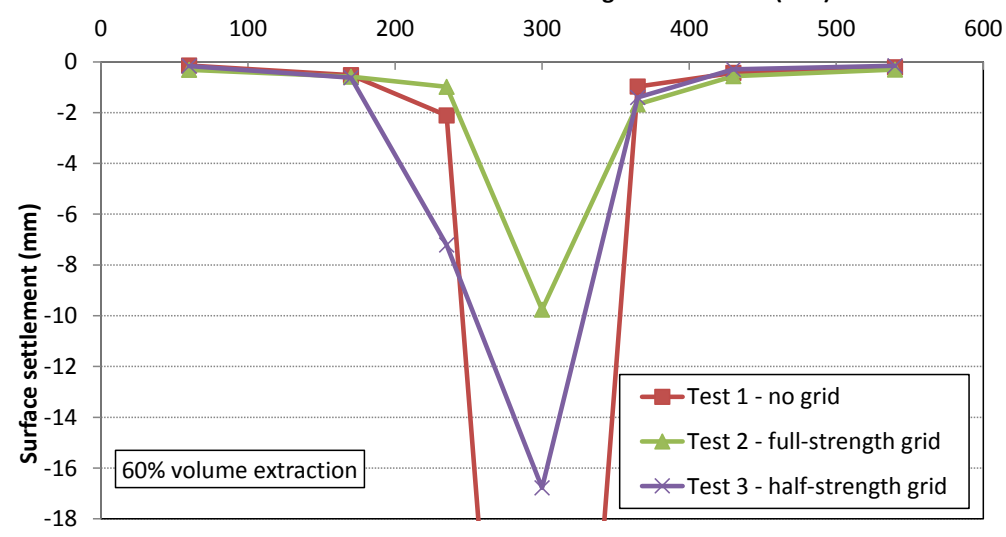

Fig. 5 Surface settlement profiles for various rates of volume extraction - Tests 1-3 
At 5\% volume extraction, the settlements in all three tests were small and of similar magnitude. At $20 \%$ volume extraction a clear distinction between the performances of the different tests could be seen. The settlements of the unreinforced and full-strength reinforced mattresses were similar, but less than that of the half-strength mattress. At $40 \%$ volume extraction the settlements of the two reinforced mattresses were considerably larger than at $20 \%$ volume extraction. There was also a clear distinction between the settlement of the unreinforced versus the reinforced mattresses (Test 1 and Test 2). The settlement of the full-strength reinforced mattress (Test 2) was now much larger than that of the unreinforced (Test 1). It should be noted that part of the unreinforced soil mattress in Test 1 collapsed into the underlying cavity shortly after this stage at $41 \%$ volume extraction to form a cover collapse sinkhole. At $60 \%$ volume extraction the settlement of the full-strength mattress (Test 2) was still considerably less than that of the half-strength mattress (Test 3 ).

As mentioned, the strength and tensile stiffness of the geosynthetic affected the performance of a reinforced soil mattress. This was illustrated at $60 \%$ volume extraction, with the displacement of the half-strength soil mattress (Test 3) settling more than the full-strength mattress (Test 2). Interestingly, the unreinforced mattress deflected significantly less than the reinforced mattresses until it suddenly collapsed. The subsidence related damage suffered by the unreinforced and reinforced soil mattresses are compared in Figure 6. In the former case an 80mm diameter cover collapse sinkhole formed while a significantly wider cover subsidence sinkhole, measuring approximately $130 \mathrm{~mm}$ in diameter, formed in the latter case. The difference in behaviour between the reinforced and unreinforced mattresses are discussed further in Sections 7.2 and 7.3.

\subsection{Displacement versus volume extracted}

The measured displacement profiles illustrate that, as expected, the mattress displacements were the largest in the middle, directly above the cavity. To assess the effect of cavity volume extraction on the maximum mattress displacements, the maximum displacements were compared against the volume extracted, illustrated in Figure 7.

Figure 7 shows that settlement commenced as soon as fluid extraction from the water-filled balloon commenced, initially at approximately the same rates in all three tests. For the unreinforced mattress (Test 1), the rate of displacement versus volume extracted was initially constant and after $10 \%$ volume loss, the rate decreased even further and stayed relatively constant up to $41 \%$ when the mattress collapsed. It is interesting to note that, up to 

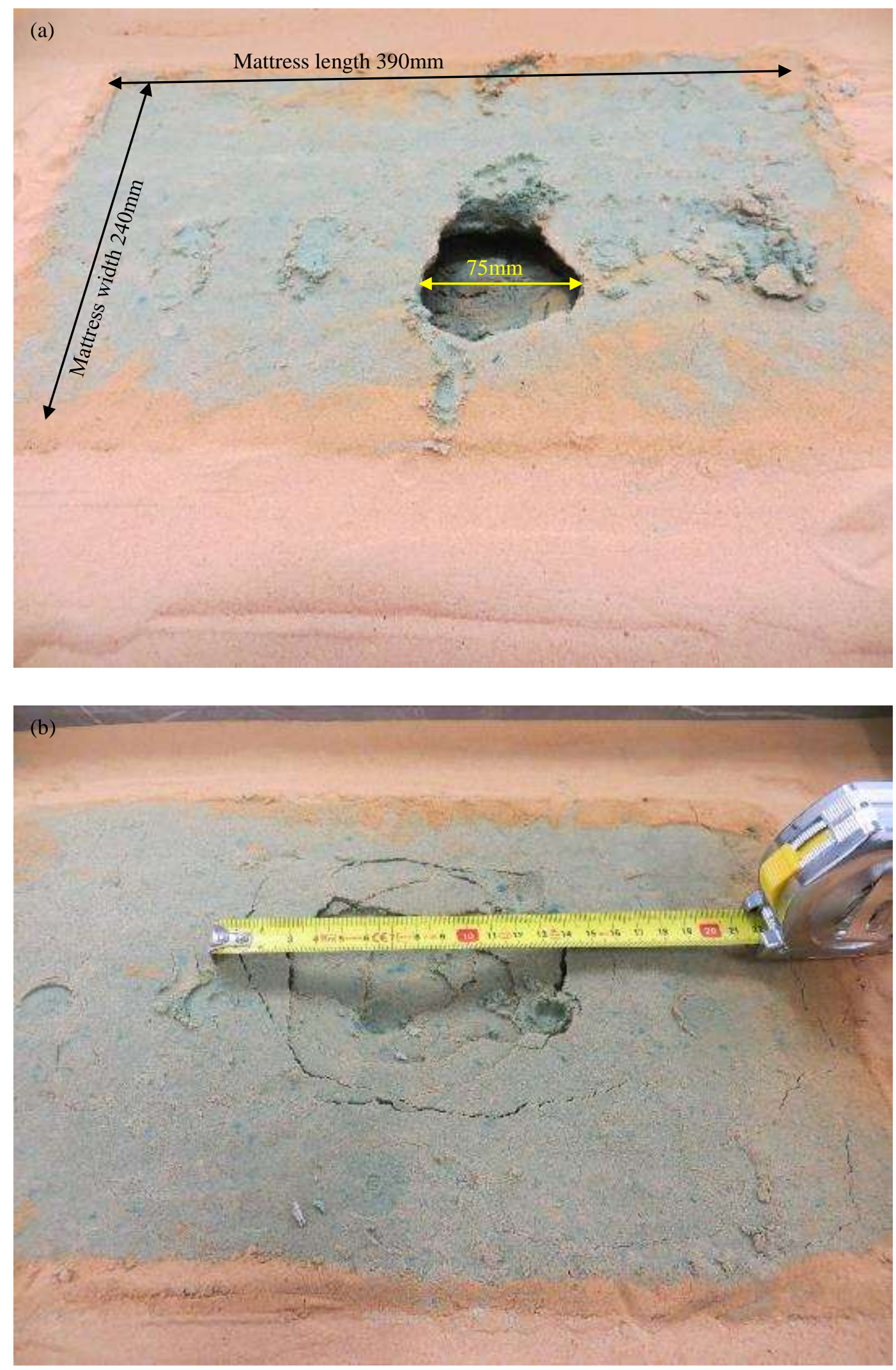

Fig. 6 Comparison of sinkhole related damage to the unreinforced (a) and reinforced (b) soil mattresses respectively. 
the point of collapse, the rate of displacement and also the maximum displacement of the unreinforced mattress (Test 1) was the smallest. This shows that the unreinforced soil mattress was initially very effective in spanning the cavity (by arching over it) at volume extractions less than $40 \%$, but failed suddenly when the volume extraction reached $41 \%$ (see Figure 7 ).

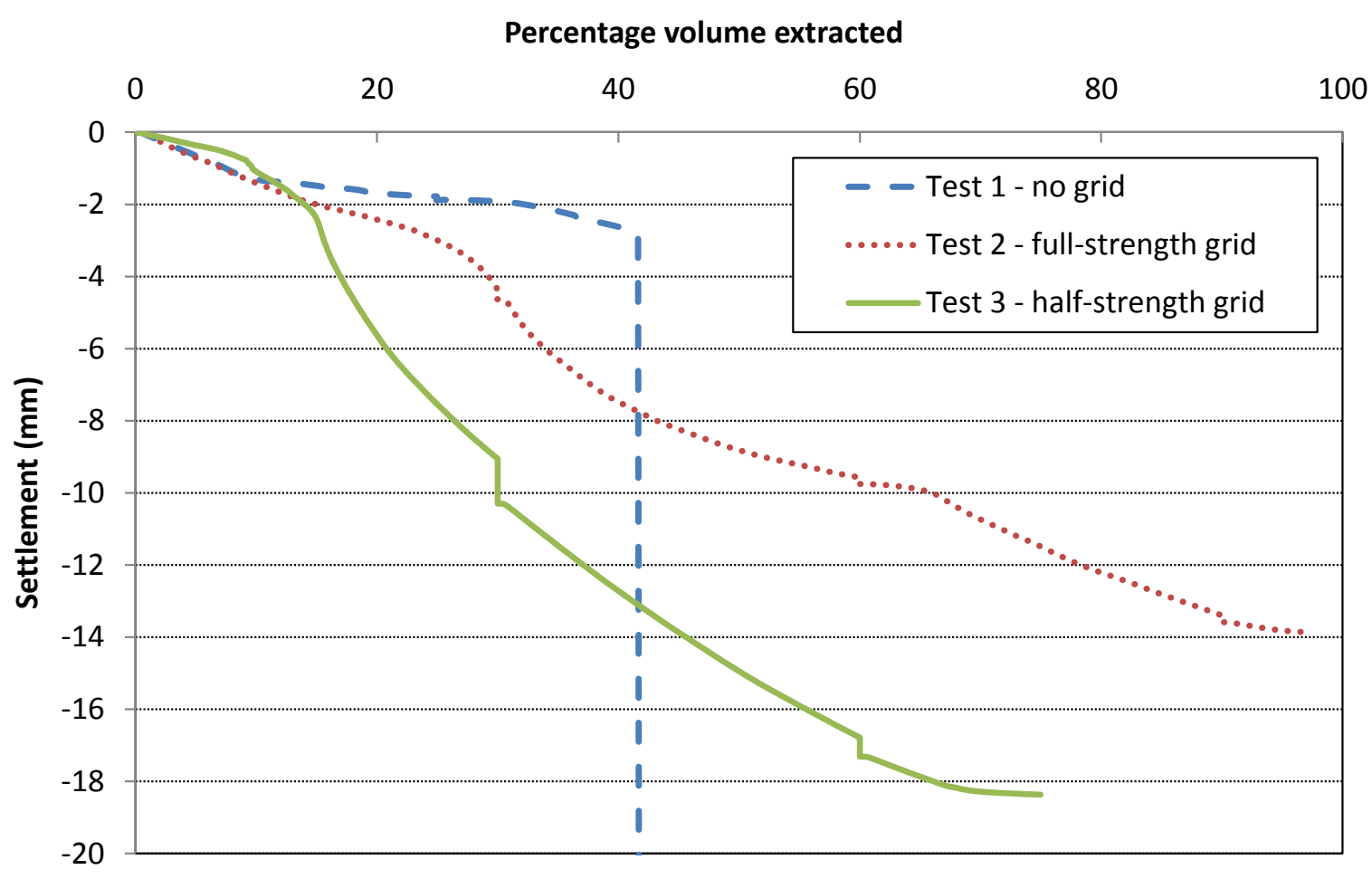

Fig. 7 Displacement versus percentage volume reduction at centre of mattress - Test 1-3

The rate of displacement versus volume extracted for the full-strength mattress (Test 2) increased approximately linearly up to approximately $25 \%$ volume extraction, similar to the unreinforced mattress (Test 1 ). After this, the rate fluctuated somewhat with increasing volume extraction. The half-strength mattress (Test 3 ) initially showed the lowest rate of displacement versus volume extracted up to $10 \%$ volume extraction, where after the rate increased rapidly and remained approximately constant for the remainder of the test. As with the full-strength grid, it is interesting to note that the rate of displacement was significantly higher than for the unreinforced soil mattress after $10 \%$. Neither of the reinforced soil mattresses failed suddenly, but both gradually suffered large displacements as volume extraction increased.

Two important observations are evident from the above: Firstly, the displacement versus volume extraction rate for the reinforced soil mattresses initially exceeded that of the unreinforced mattress. This was unexpected but could be explained by the difference in the mechanisms by which the reinforced versus unreinforced mattresses support their loads. The tensile strength of the reinforcement allowed spreading of some of the weight of the 
mattress to other parts of the mattress that would not have experienced the effect of the sinkhole had the mattress been unreinforced. This resulted in straining a larger part of the mattress. The mode of support appears to be similar to a slab-spanning mechanism brought about by the tensile strength of the reinforcement. This behaviour is different from that of the unreinforced soil mattress. The latter supported its load by means of arching, generating compressive stresses in the upper parts of the mattresses. The associated behaviour was initially more rigid than that of a spanning mechanism, but brittle and sudden failure occurred which never occurred with the reinforced mattresses, illustrating the benefit of using reinforcement.

\subsection{Vertical stress at the base of the soil mattress}

In the fourth test, a pressure mat (Tekscan sensor type 5101) was installed to observe the effect of volume extraction from the balloon on the vertical stress at the base of the soil mattress. The plan dimensions of the measuring area of the pressure mat were $112 \mathrm{~mm}$ x $112 \mathrm{~mm}$. In Figure 8 results are compared to strain readings from a single roughened strain gauged brass strip placed underneath the full-strength reinforced mattress to provide an indication of when the reinforcement began to experience tension. The primary vertical axis in Figure 8 presents the average vertical stress at the base of the soil mattress against the percentage volume extracted, with the tensile strain recorded in the brass strip on the secondary vertical axis.

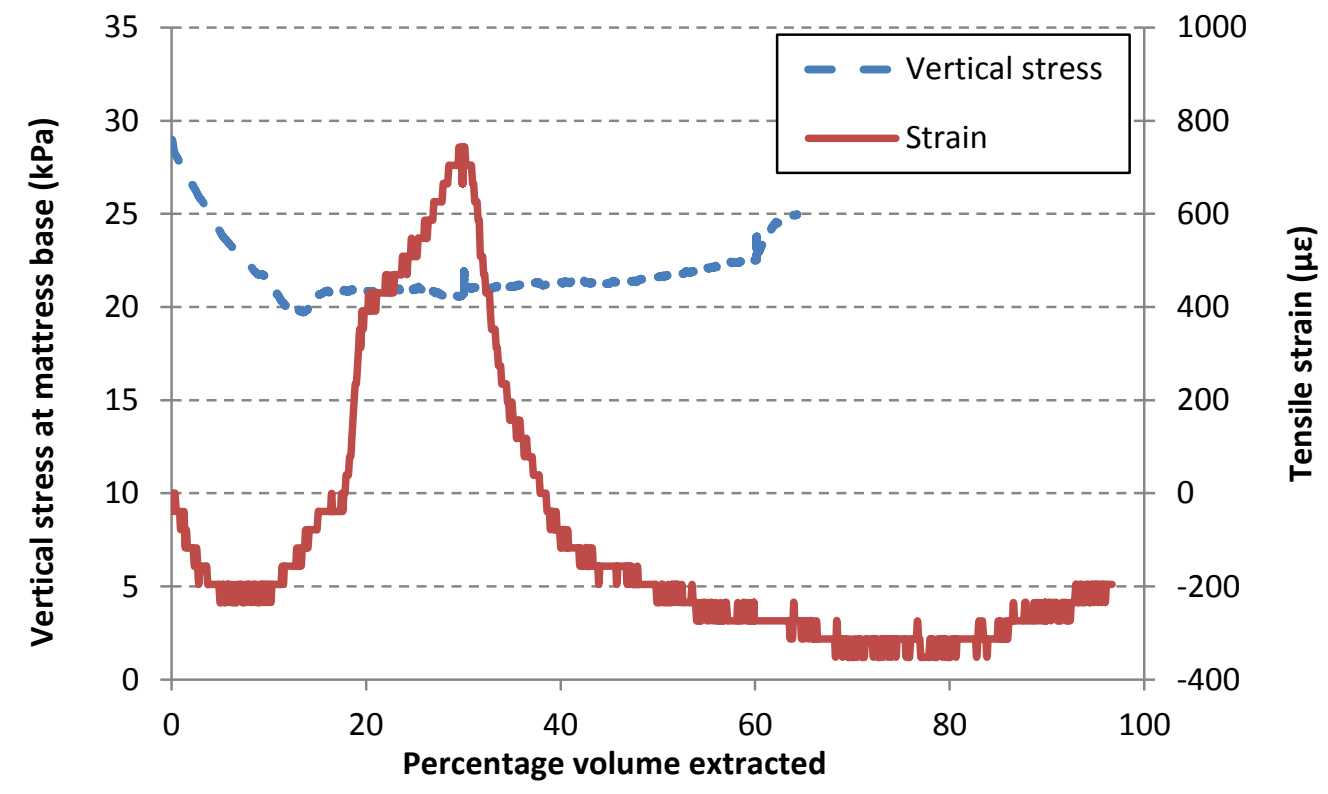

Fig. 8 The effect of volume extraction on vertical stress and tensile strain at the base of the soil mattress for the full-strength grid. 
The average pressure decreased at an approximately constant rate up to about $14 \%$ volume extraction. Thereafter, the pressure remained essentially constant, increasing only slightly as volume extraction increased by a further $45 \%$. At $60 \%$ volume extraction, the pressure increased for a short while before the test ended.

The decrease in vertical stress at the base of the mattress during the first $14 \%$ of volume extraction is thought to be associated with the redistribution of stresses as an arching mechanism developed above the cavity. In order to maintain equilibrium, the reduction in cavity pressure and associated reduction in vertical stress at the base of the mattress would have been counteracted by increased near-horizontal compressive stresses in the arching soil and an increase in the vertical stress along the perimeter of the arch (see Figure 9 and Figure 10). Figure 7 illustrates

(a)

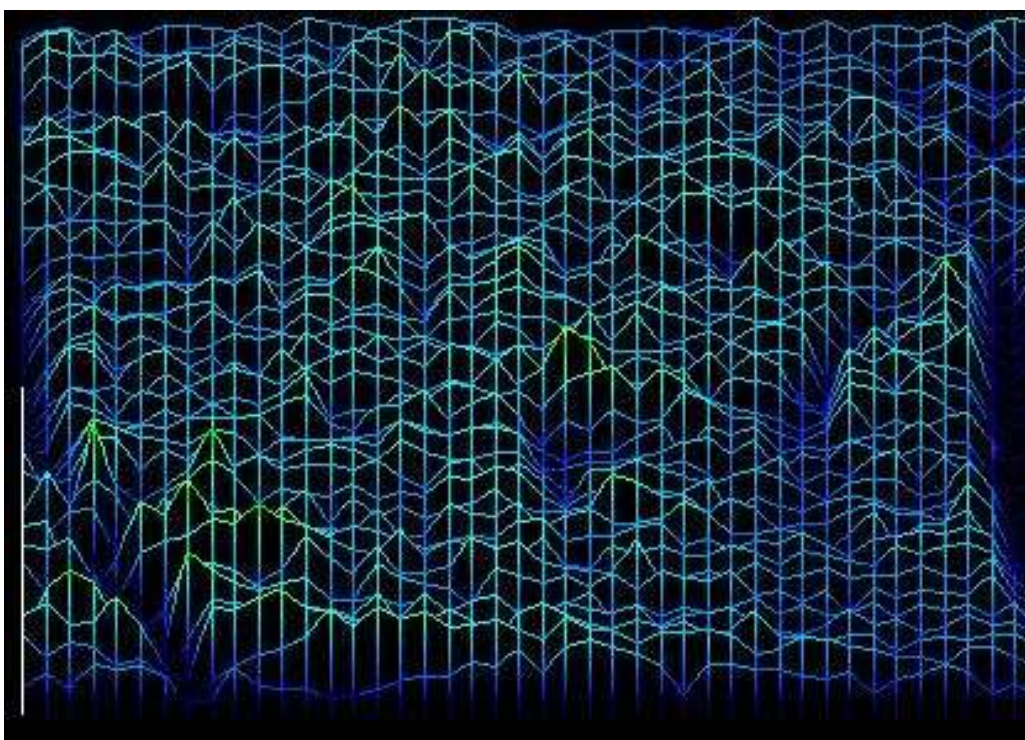

(b)

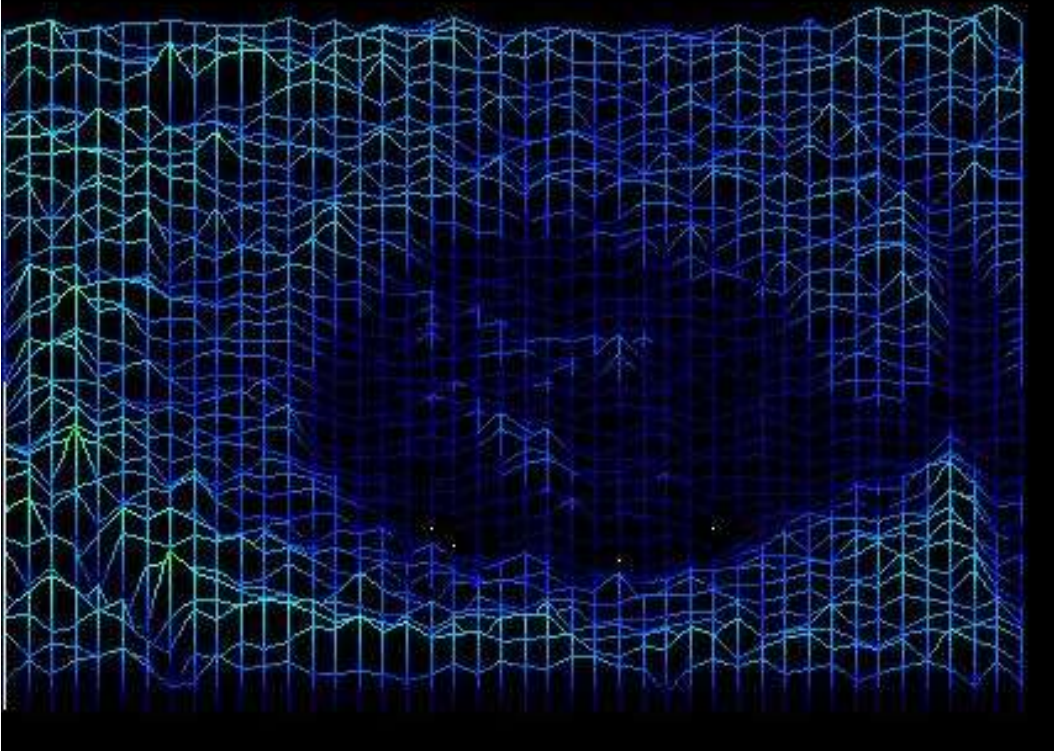

Fig. 9 3D plot of the pressure distribution on the pressure mat at $0 \%$ and $14 \%$ volume extraction illustrating qualitatively the vertical stress redistribution in response to cavity formation 
similar behaviour for the reinforced and unreinforced mattresses up to $14 \%$ volume extraction, with tensile reinforcement not having an effect yet.

Readings from the strain gauged brass strip were very sensitive to bending of the strip. Not much significance is attached to the actual strain values in Figure 8, but the sudden change in strain above $17 \%$ volume extraction is thought to reflect the instance where the load bearing mechanism of the mattress changed from one of arching to spanning (see idealised mechanisms illustrated in Figure 10). This point corresponds well with the volume extraction value at which stabilisation of the vertical stress at the base of the mattress occurred.

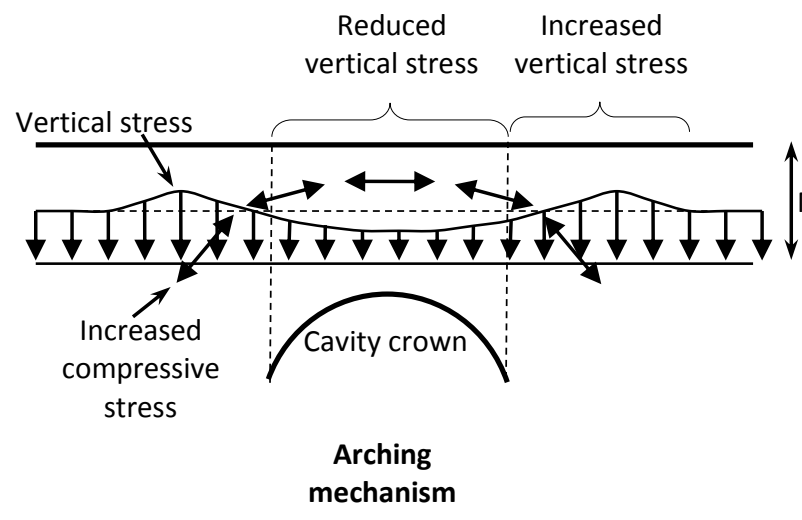

No tensile reinforcement

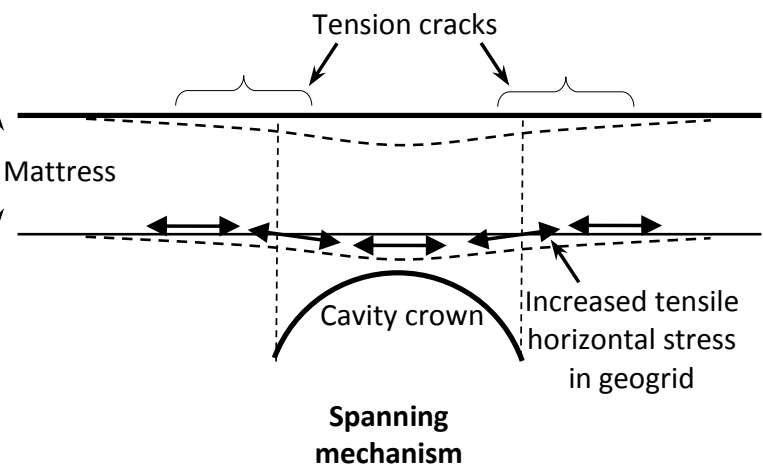

Tensile reinforcement present

Fig. 10 Idealised load support mechanisms with and without tensile reinforcement

With a further extraction of fluid from the balloon, the average vertical stress at the base of the mattress remained approximately constant as further vertical stress reduction could not be supported. The settlement of the reinforced mattresses exceeded that of the unreinforced mattress with further volume extraction, suggesting that the reinforcement began to take up tension which was distributed across the mattress.

\subsection{Performance requirements on dolomite}

SANS 1936 (2012) sets limits to acceptable sinkhole-related damage that may be suffered by structures built on sites of different hazard classes, stipulating that a sinkhole may not envelop the building or result in the toppling or sliding failure of the building or a portion thereof into such a hole and that there must be sufficient time for occupants to safely escape from the structure after the occurrence of the sinkhole. The results of the centrifuge testing suggest that unreinforced mattresses will not satisfy the code's requirements without assistance from other precautionary measures such as a specially designed concrete raft foundation as the unreinforced mattress failed suddenly with very little warning. Given the diameter of the cover subsidence sinkhole imposed, the 
reinforced mattresses, on the other hand, did not fail suddenly and gave ample warning of the developing sinkhole.

Adding tensile reinforcement at the bottom of the mattress changed the mode of load resistance from an arching to a spanning mechanism. The latter suffered large settlements, but did not fail suddenly. Further investigation is required to determine whether the rigidity of the arching mechanism can be maintained to greater volume extraction ratios before the arch collapses by perhaps adjusting the position of the reinforcement within the mattress or the mattress thickness.

The results represented the development of a cover subsidence sinkhole of $5 \mathrm{~m}$ diameter formed below the centre of a $2 \mathrm{~m}$ thick reinforced mattress (full scale dimensions). The use of tensile reinforcement in the mattress changed the nature of the final sinkhole manifestation from a cover collapse to cover subsidence event, thereby reducing the severity of the impact. It should be noted that beneficial effects of the reinforcement will reduce with increasing sinkhole diameter or should the sinkhole form off-centre relative to the mattress. These aspects were not investigated in this study.

\section{CONCLUSIONS}

A series of physical model tests was carried out in the geotechnical centrifuge to investigate the effect of tensile reinforcement in the base of a soil mattress spanning a cover subsidence sinkhole. The following conclusions are presented:

- Commencement of volume extraction from the model cavity was immediately accompanied by a reduction in the vertical stress at the base of the mattress, reflecting the development of an arching mechanism as illustrated in Figure 10. At approximately 14\% volume extraction, the vertical stress had stabilised. With further volume extraction the settlement of the reinforced mattresses exceeded that of the unreinforced mattress, suggesting that the reinforcement began to take up tension which was distributed across the mattress. This is supported by the tensile strain readings recorded at the base of the full-strength reinforced mattress.

- The settlements suffered by the reinforced soil mattresses exceeded that of the unreinforced soil mattress up to the point where the unreinforced mattress failed suddenly under its own weight into the underlying cavity. In the model test this occurred at a cavity volume extraction value of $41 \%$. The reinforced soil mattresses continued to span the cavity and did not collapse during the tests. However, significant cracking was observed at the surface of the reinforced soil mattresses. The cracking occurred in a circular pattern at the surface and resembled cracking due to shear (see Figure 6). 
- Soil arching occurred within the unreinforced soil mattress prior to failure. The mattress bridged the cavity by means of arching until the arch grew too thin or weak and then collapsed into the underlying cavity without warning. The addition of tensile reinforcement changed the load bearing mechanism from one of arching to one of spanning beyond $14 \%$ volume extraction.

- The total settlement of the soil mattress reinforced with the stronger and stiffer reinforcement was less than that of the weaker and less stiff reinforcement. Both reinforcement strengths were, however, strong enough to allow the soil mattress to span the cavity without collapsing.

- The deformation suffered by the reinforced mattresses provided early warning of the developing cavity, while the unreinforced mattress did not provided such warning, further illustrating the benefit of tensile reinforcement in a soil mattress.

- In terms of deflection, the unreinforced soil mattress performed better than the reinforced soil mattresses up to the point where the unreinforced soil mattress collapsed. Tensile reinforcement allowed some of the self-weight of the mattress to be transferred to other parts of the mattress that would not have experienced these loads, causing the mattress to settle more. This changed the load bearing mechanism from one of arching to spanning and was associated with large deformations. The inclusion of reinforcement resulted in a ductile system where indications of impending failure appeared well in advance of any failure that may occur. By contrast, the unreinforced soil arch resulted in less initial signs of distress, followed by sudden collapse.

- Adjusting the position of the reinforcement inside the mattress may allow the advantages of arching to be reaped to a larger volume extraction value, while still preventing catastrophic failure of the mattress. This is a topic for future research.

\section{REFERENCES}

Archer, A. 2014. Using small strain stiffness to predict the settlement of shallow foundations on sand. MEng disseration. University of Pretoria.

Beck, B.F. and Sayed, S. 1991. The sinkhole hazard in Pinellas County: A geologic summary for planning purposes. Florida Sinkhole Research Institute. University of Central Florida, Orlando, Fl.

Brink, A B A 1979. Engineering Geology of Southern Africa. Pretoria: Building Publications

BS 8006, 1995. Code of practice of strengthened/reinforced soils and other fills. British Standards Insitution.

Buttrick, D B, Trollip, N Y G, Watermeyer, R B, Pieterse, N D\& Gerber, A G 2011. A performance based approach to dolomite risk management. Environmental Earth Sciences, 1127-1138.

Buttrick, D B, Van Schalkwyk, A, Kleywegt, R J \& Watermeyer, R B 2001. Proposed method for dolomite land hazard risk assessment in South Africa. Journal of the South African Institution of Civil Engineering, 43, $27-$ 36.

Culshaw, M.G. and Waltham, A.C. 1987. Natural and artificial cavities as ground engineering hazards. Quarterly Journal of Engineering Geology, London, Vol 20, pp. 139-150. 
Department of Transport. 1986. Method A7 - The determination of the maximum dry density and optimum moisture content of gravel, soil and sand. TMH1- Standard methods of testing road construction materials. Pretoria, South Africa: Department of Transport, 27 - 34.

Domone, P. \& Illston, J. 2010. Construction Materials - Their nature and behaviour. (4th ed.). Great Britain: Spon Press.

Giraud, H. 1997. Renforcements des zones d'effondrement localisé-Modélisations physique et numérique. The University of Genoble, France.

Giroud, J P, Bonaparte, R, Beech, J F \& Gross, B A. 1990. Deisgn of soil layer-geosynthetic systems overlying voids. Geotextiles and Geomembranes, 9, 11-55.

Jacobsz, S.W. 2013. The stiffness of residual dolomite from large scale surcharge trials. Quarterly Journal of Engineering Geology and Hydro-Geology, 46, pp 75-86, DOI: 10.1144/qjegh2012-036.

Jacobsz, S.W., Kearsley, E.P. \& Kock, J.H.L. 2014. The geotechnical centrifuge facility at the University of Pretoria. Proc 8th International Conference on Physical Modeling in Geotechnics, Perth. CRC Press, pp169-174.

Jennings, R E, Brink, A B A, Louw, A \& Gowan, G D 1965. Sinkholes and subsidences in the Transvaal dolomite of Souh Africa. Proceedings, Sixth International Conference of Soil Mechanics and Foundation Engineering, Montreal, pp. 51-54.

Johnson, M.R., Anhaeusser, C.R. and Thomas, R.J. 2006. The Geology of South Africa. Geological Society of South Africa and Council for Geoscience. Pretoria.

Koerner, R M 2005. Designing with Geosynthetics. (5th ed.). Upper Saddle River, New Jersey, USA: Pearson Prentice Hall.

Lord Jr, E 1987. Geosynthetic/Soil Studies using a geotechnical centrifuge. Geotextiles and Geomembranes, 6 , 133-156.

Ponomaryov, A \& Zolotozubov, D 2013. Several approaches for the design of reinforced bases on karst areas. Geotextiles and Geomembranes, 1-4.

Poorooshasb, H B 1991. Load settlement response of a compacted fill layer supported by a geosynthetic overlying a void. Geotextiles and Geomembranes, 10, 179-201.

Richardson, S 2013. Sinkhole and subsidence record in the Chuniespoort group dolomite, Gauteng, Soth Africa, MSc Dissertation edn, The University of Pretoria, Pretoria.

Rowe, R K \& Jones, C J F P 2000. Geosynthetics: Innovative materials and design. ISRM International Symposium, International Society of Rock Mechanics.

SABS 2012. The application of The National Building Regulations. South African National Standard 10400. Pretoria.

SABS 2012. Development of dolomite land. South African National Standards 1936. Pretoria

SABS 2006. The design and construction of reinforced soils and fills. South African National Standard 207. Pretoria.

Sherif, W A \& Jones, C J F P 1996. Design of reinforced fill systems to support footings overlying cavities. Geotextiles and Geomembranes, 14, 57-72.

Tekscan 2014 , I-Scan System [Homepage of Tekscan Inc.], [Online]. Available:http://www.tekscan.com/products/industrial/pressure-distribution-measurement-system [Accesed on 1 May 2014]. 
Van Schalkwyk, A 1981. Ontwikkelingspatroon en risiko-evaluasie in dolomietgebiede. Proceedings, Seminar on the engineering geology of dolomititc area, The University of Pretoria, 9-24.

Wagener, F V M. 1984. Engineering construction on dolomite. Marshalltown: Geotechnical division of the South African Institution of Civil Engineers.

Wagener, F V M. \& Day, P W 1986. Construction on dolomite in South Africa. Environmental Geology and Water Sciences. 8, 83-89.

Wang, M C, Feng, Y X \& Jao, M 1996. Stability of geosynthetic-reinforced soil above a cavity. Geotextiles and Geomembranes, 14, 95-109. 